\title{
Efficiency Determination of Compressor Embedded Induction Motors
}

\author{
Carlos A. C. Wengerkievicz ${ }^{1}$, Cristian F. Mazzola ${ }^{1}$, Nelson Sadowski ${ }^{1} \mathbb{D}$, Nelson J. Batistela $^{1}$, \\ Ernane Silva ${ }^{2}$, Cesar J. Deschamps ${ }^{2} \mathbb{C}$ \\ ${ }^{I}$ GRUCAD/EEL/CTC, Federal University of Santa Catarina, P.O. Box 476, 88040-970, Florianópolis, SC, \\ Brazil.c.a.correa@posgrad.ufsc.br,cristian@eel.ufsc.br,nelson.sadowski@ufsc.br,jhoe.batistela@ufsc.br \\ ${ }^{2} P O L O$ Research Laboratories for Emerging Technologies in Cooling and Thermophysics, Federal University \\ of Santa Catarina,88048-300,Florianopolis, SC,Brazil.ernane@polo.ufsc.br,deschamps@polo.ufsc.br
}

\begin{abstract}
Compressors operating in refrigeration systems, typically with built-in induction motors, represent an important energy demand. The applicability of standard methods for efficiency determination of induction motors is limited in this context by the constructive characteristics of these motors, such as the shared compressor frame and the inaccessibility of the shaft. The main contributions of this paper are to provide an overview of standard and alternative methods for efficiency testing of single and polyphase motors, according to technical standards and to the state of the art, and to offer guidelines for the method selection. The options cover dynamometer tests, loss segregation and equivalent circuit methods, some even applicable without direct access to the motor. Experimental application examples in single and threephase motors are presented. Beyond the context of compressors, the discussion is relevant for inaccessible motors in general.
\end{abstract}

Index Terms - Compressor, efficiency, induction motor, losses, tests.

\section{INTRODUCTION}

Cooling systems are estimated to correspond to $20 \%$ of the energy consumption of buildings worldwide and are the fastest growing end-use in this sector [1]. These systems are commonly based on gas compression and consist of at least a compressor, a condenser, an evaporator and an expansion device [2]. An extensive survey on air conditioners [3] pointed out that $80 \%$ to $87 \%$ of the steadystate input power of these appliances corresponds to the compressor, the remaining being absorbed by fans and controls. Energy efficiency policies are expected to double the average efficiency and reduce in $45 \%$ the energy demand of cooling systems by 2050 [1], evidencing the importance of efficiency studies focused on these devices.

Compressors embedded in household refrigeration systems are commonly driven by two-pole induction motors [4], either single-phase or three-phase, although more sophisticated models employ permanent magnet machines. An internal scheme of a hermetic rotary compressor is shown in Fig. 1. The vertical stator is assembled by interference fit into the hermetically closed compressor frame, and 
the rotor is supported by plain bearings only on the bottom part of the shaft, close to the compression mechanism. In scroll and reciprocating compressors, the mechanism may be located on the top, and upper bearings between the motor and the mechanism can be present. The bearings are lubricated by oil pumped from the bottom of the compressor, and the motor is cooled by the circulating fluid and through the frame. An overview of compressor types is presented in [5].

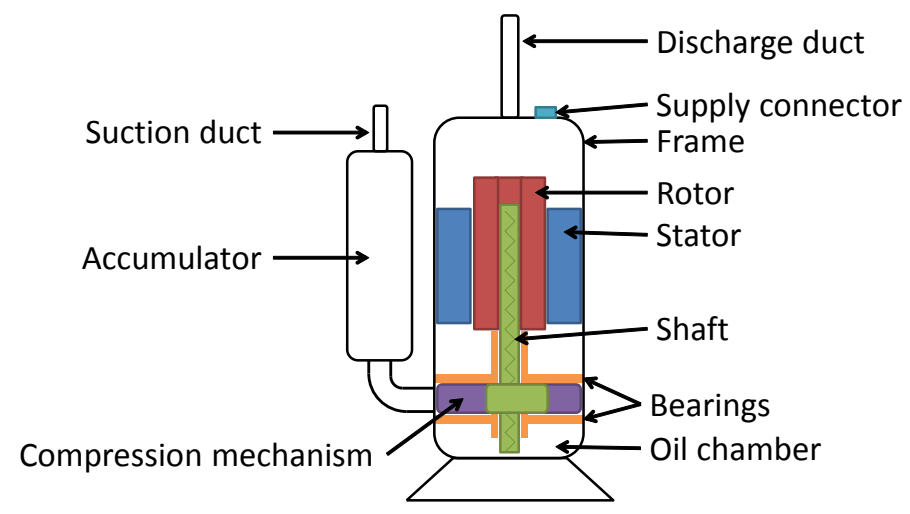

Fig. 1. Simplified scheme of a rotary compressor.

The compressor total efficiency can be regarded as the product of three stages[6], [7]: i) motor efficiency, which is the focus of this work and is related mainly to joule and core losses; ii) mechanical efficiency, related to friction loss in the bearings and mechanisms and also to oil pumping; and iii) compression efficiency, due to heat and volume losses during the compression process. The value of the first term is often a required input for the determination of the other two [6][10]. Although standard methods for efficiency determination of induction machines are provided in technical standards [11]-[13], some difficulties in their application arise from the constructive features of these motors. Prior to the compressor assembly, the motor does not possess its own frame to be tested individually, thus requiring mechanical support from a custom structure capable of maintaining the same airgap setting as in the original frame. Once mounted to the compressor frame, most machines may not run horizontally due to the bearing and lubrication systems, therefore limiting dynamometer tests to vertical test benches or requiring test methods without torque measurements. Moreover, machines with single-sided shafts, such as those employed in rotary compressors, cannot be coupled to dynamometers unless some sort of shaft extension is installed. Finally, after the compressor is assembled, it is practically impossible to access the motor or to remove it from the compressor without damaging the frame.

Similar difficulties have been reported in [14], where tests with a rotating jig are performed for quality assessment of BLDC motors. A summary of test methods for fractional horsepower motors has been presented in [15] on a broader context, without considering the restrictions of inaccessible machines such as compressor mounted motors. In[6], the efficiency of the electric motor is simply assumed as a constant value of $85 \%$ to determine the efficiency of the remaining stages. In [8], the analysis of losses is achieved by inserting temperature, pressure and speed sensors inside the compressor. Similar analyses are performed in [7], [9], [10] employing efficiency curves of a variable 
speed drive obtained from manufacturer data, which are seldom available. Semi-empiric models of scroll compressors are determined based on external measurements during calorimeter tests in [16], [17]. The parameters that characterize the constant and load-dependent electromechanical losses, along with other model parameters, are determined by minimization of the difference between external measurements and its calculated values.

The main contribution of this paper is to provide an overview of efficiency test methods applicable to single and polyphase induction motors embedded in hermetic compressors, and to propose guidelines for the choice of the most appropriate method according to the circumstances and to the characteristics of the compressor. The most important methods found in the literature are presented in Section II. Practical examples of dynamometer testing are exposed in Section III, and its results are presented and discussed in Section IV. Beyond the scope of compressors, the discussion may apply to other contexts of inaccessible motors.

\section{METHODS FOR EFFICIENCY DETERMINATION OF INDUCTION MOTORS}

The main standard methods for efficiency determination of induction machines are described in IEEE standards 112 [11] and 114 [12] and in IEC 60043-2-1 [13]. The former two treat separately polyphase and single-phase machines, respectively, while the latter covers both types. The testing procedures for polyphase machines are well-established and offer many possibilities, being very similar in [11], [13]. In contrast, the standards for single-phase machines are much more simplified and do not contemplate many situations, as will be presented later on. Some techniques for singlephase machines have been developed in fundamental works such as [18], [19], yet they have not been consolidated in standards. Recent studies were devoted to the nonintrusive efficiency estimation of induction machines [20] and to the determination of equivalent circuit parameters by alternative means [21], [22]. Their relevance becomes limited in a context where bench tests are possible, thus they were excluded from the scope of the present discussion. A summary of test methods for polyphase induction motors (PPIM) and single-phase induction motors (SPIM) is presented as follows, with special focus on the necessary tests and measurements. Detailed calculations are available in [15] and in the cited references.

\section{A. Direct method (Input Output)}

The efficiency $(\eta)$ of an electric motor is defined as the ratio between the output power $\left(P_{\text {out }}\right)$ supplied to the mechanical load and the input power $\left(P_{i n}\right)$ absorbed from the power supply, as expressed in (1). The simplest way to determine the efficiency of an electric motor is by the so-called direct method, where the output power is defined as the product of the torque $(T)$ and the shaft speed $\left(\omega_{r}\right)$ measured during dynamometer tests, as indicated in (2). The method is recommended for fractional horsepower PPIM [11] and for SPIM in general [12], [13].

$$
\eta=\frac{P_{o u t}}{P_{\text {in }}}
$$




$$
P_{\text {out }}=T \omega_{r}
$$

The procedure starts with a load temperature test to determine the steady-state temperature at rated condition. The stator resistance and the ambient temperature are also measured. The machine is then operated at six load levels: approximately $25 \%, 50 \%, 75 \%$ and $100 \%$ of the rated load, and two additional points between $100 \%$ and $150 \%$. At each level, readings of voltage, current, input power, frequency, speed, torque, ambient temperature and stator winding temperature are recorded. The temperature of the stator windings can be inferred from its resistance variation.

The efficiency is computed through (1) and (2) after corrections of torque, input power and speed, related to the dynamometer drag, to the temperature influence on the stator and rotor winding resistances, and to the supply frequency deviations during the tests. The importance of dynamometer correction for fractional horsepower machines is highlighted in [15]. The stator winding resistance $\left(R_{s}\right)$ is corrected to the specified temperature $\left(t_{s}\right)$ by (3) as a function of the resistance $\left(R_{t}\right)$ at test temperature $\left(t_{t}\right)$ and of the constant $k_{1}$, which is $234.5{ }^{\circ} \mathrm{C}$ for copper windings and $225{ }^{\circ} \mathrm{C}$ for aluminum. The input power correction $\left(C_{P i n}\right)$ as $(4)$ is simply the difference between the stator joule losses at $t_{s}$ and at $t_{t}$ with each measured line current $I_{1}$. The corrected slip $\left(s_{s}\right)$ is calculated in a similar way by (5), where $k_{2}$ depends on the rotor winding material and $s_{t}$ is the slip at test temperature.

$$
\begin{aligned}
R_{s} & =R_{t} \frac{\left(t_{s}+k_{1}\right)}{\left(t_{t}+k_{1}\right)} \\
C_{P \text { in }} & =I_{1}^{2}\left(R_{s}-R_{t}\right) \\
S_{s} & =s_{t} \frac{\left(t_{s}+k_{2}\right)}{\left(t_{t}+k_{2}\right)}
\end{aligned}
$$

The main advantages of this method are its generality and standardized character. In the context of compressor motors, the required torque measurement represents the strongest drawback.

\section{B. Segregation of losses with or without torque measurement}

In the "indirect" method, the output power is defined by (6) as the input power minus the total loss $P_{\text {loss }}$, equal to the sum of five types of losses determined individually: stator joule loss $\left(P_{j 1}\right)$, rotor joule loss $\left(P_{j 2}\right)$, core loss $\left(P_{c}\right)$, friction and winding loss $\left(P_{f w}\right)$ and stray-load loss $\left(P_{s l l}\right)$.

$$
P_{\text {out }}=P_{\text {in }}-P_{\text {loss }}
$$

According to the standards, the segregation of losses can be performed with or without torque measurements. The first option, featured in method B of [11] (input output method with segregation of losses) and similarly in [13], is the preferred standard method for integral horsepower PPIM. It comprises the same temperature and load tests as the direct method, plus a no-load test, when the machine operates uncoupled at decreasing voltage levels from $125 \%$ of the rated value down to the point where the current increases, as readings of voltage, current and input power are recorded.

At any test condition, the stator joule loss is calculated as (7), where $m$ is the number of phases.

$$
P_{j 1}=m I_{1}^{2} R_{t}
$$


From the no-load test, the intercept of the linear regression of $P_{i n}-P_{j 1}$ against the voltage squared is attributed to $P_{f w}$. The remaining no-load power at rated voltage is attributed to $P_{c}$, since $P_{j 2}$ and $P_{s l l}$ are assumed to be negligible in this condition. For each point of the load test, $P_{j 2}$ is determined as (8), where $s$ is the per-unit slip, and $P_{\text {sll }}$ is estimated as the difference between the total apparent $\operatorname{loss}\left(P_{\text {in }}\right.$ $\left.T \omega_{r}\right)$ and the sum of the remaining types, as expressed in (9). A linear regression of these values versus the squared torque yields a fitted value. Temperature and dynamometer corrections, similar to those of the direct method, are also applicable. Finally, the efficiency is computed through (1) and (6). As demonstrated, the torque is only measured to enable the determination of $P_{\text {sll }}$ by exclusion.

$$
\begin{gathered}
P_{j 2}=s\left(P_{i n}-P_{j 1}-P_{c}\right) \\
P_{s l l}=P_{i n}-T \omega_{r}-\left(P_{j 1}+P_{c}+P_{j 2}+P_{f w}\right)
\end{gathered}
$$

An alternative approach without torque measurement is described in methods E and E1 of [11] and in their IEC counterparts [13]. In method E, the stray-load loss is measured directly in backward rotation and removed rotor tests, while in method $\mathrm{E} 1$ their value at rated condition is simply assumed as a percentage of the rated output power. The IEC standard [13] also features the EH-Star method, through which the stray load loss is determined in a no-load test with asymmetric supply. This is especially interesting in the studied context, once it enables the precise determination of losses from electrical and speed measurements only, although load imposition is still necessary.

In the case of SPIMs, the IEEE Std. 114 [12] contemplates only motors with a single run winding, thus not covering permanent capacitor, shaded-pole and split-phase motors. In contrast to the polyphase case, $P_{j 2}$ is not negligible at no-load due to the negative sequence rotor currents induced by the backward field [15]. Therefore, an additional locked-rotor test (LRT) at 50\% of rated voltage is required. The total no-load joule loss $P_{j N L}$ for a SPIM is calculated as (10), where $P_{L R}$ and $I_{L R}$ are respectively the locked-rotor input power and current. The determination of $P_{f w}, P_{c}$ and $P_{j 2}$ in SPIM is similar to the polyphase case. If torque measurements are available, $P_{s l l}$ can be determined by elimination as in method $\mathrm{B}$, or it can be simply assumed as $1.8 \%$ of the rated output power.

$$
P_{j N L}=\frac{I_{1}^{2}}{2}\left(R_{1}+\frac{P_{L R}}{I_{L R}^{2}}\right)
$$

Early methodologies developed by Veinott [18] contemplate SPIMs with one or more run windings. For single winding motors, aside from resistance measurements, no-load and load tests (without torque measurement), the determination of three constants in no-load and locked-rotor tests at rated voltages required: $R_{2}$, the rotor resistance referred to the stator winding; $X$, the ideal locked rotor reactance if $R_{2}$ were zero; and $X_{0}$, the stator reactance with the rotor winding open-circuited. The total no-load joule loss can be calculated through (11), and the remaining no-load losses $\left(P_{c}\right.$ and $\left.P_{f w}\right)$ are separated in the conventional no-load test with decreasing voltage. For each point of the load test, $P_{j 2}$ is calculated through (12). The stray-load losses neglected, which is justified by the small variation of stator current from no-load to full load current and by measurement precision issues. 


$$
\begin{gathered}
P_{j N L}=\left[R_{1}+\frac{R_{2}}{2}\left(1-\frac{X}{X_{0}}\right)\right] I_{1}^{2} \\
P_{j 2}=0.5\left(1-\frac{X}{X_{0}}\right) R_{2} I_{1}^{2}\left[\frac{1}{1+\left(\frac{R_{2}}{X_{0} s}\right)^{2}}+\frac{1}{1+\left(\frac{R_{2}}{X_{0}(2-s)}\right)^{2}}\right]
\end{gathered}
$$

For multiple winding motors, the method presented in [18] also requires the winding ratio $a$ between the auxiliary and the main winding. This value, when not available from design data, can be measured by running the motor at no-load on the main winding only and measuring the voltage on the auxiliary winding, and then vice versa. The square root of the product of the measured voltage ratios yields the winding ratio. The values of $P_{c}$ and $P_{f w}$ are determined from the single winding procedure employing only the main winding. In the load test, the stator joule loss for each winding is calculated based on the respective DC resistances and currents. The expressions presented in [18] for the rotor joule losses due to the forward and backward rotating fields, $P_{j 2+}$ and $P_{j 2-}$ respectively, can be simplified to (13) and (14), where $\mathbf{I}_{m}$ and $\mathbf{I}_{a}$ are the main and auxiliary current phasors.

$$
\begin{gathered}
P_{j 2+}=\frac{0.5\left(1-\frac{X}{X_{0}}\right) R_{2}}{1+\left(\frac{R_{2}}{X_{0} s}\right)^{2}}\left|\mathbf{I}_{m}-j a \mathbf{I}_{a}\right|^{2} \\
P_{j 2-}=\frac{0.5\left(1-\frac{X}{X_{0}}\right) R_{2}}{1+\left(\frac{R_{2}}{X_{0}(2-s)}\right)^{2}}\left|\mathbf{I}_{m}+j a \mathbf{I}_{a}\right|^{2}
\end{gathered}
$$

The absence of torque measurement is a strong advantage of the Veinott methods. Their main drawback is the non-standard character, which may limit its application.

\section{Equivalent circuit methods}

The efficiency can also be computed from the equivalent circuit. For PPIM, the methods F and F1 of [11] recommend the circuit depicted in Fig. 2, where $\mathbf{V}_{1}$ is the phase voltage phasor, $R_{1}$ and $R_{2}$ the resistances of the stator and rotor windings, respectively, $X_{1}$ and $X_{2}$ are the respective stator and rotor leakage reactances, $X_{m}$ is the magnetizing reactance and $R_{c}$ accounts for the core losses. All values are referred to the stator. The friction and windage loss and the stray-load loss are not represented and must be subtracted a posteriori from the converted power, dissipated in the variable resistance in the rotor branch. The test procedure consists on stator resistance measurements, a no-load test and an impedance test, which can be one of the following: i) LRT at rated current and at maximum of $25 \%$ of rated frequency; ii) LRT at rated current at three frequencies: rated, $50 \%$ and at maximum $25 \%$; iii) Test at rated slip, resulting from mechanical load or reduced voltage; iv) LRT at rated current and rated frequency, if none of the previous are practicable. The stray-load losses measured directly in 
method $\mathrm{F}$ and assumed as a percentage of rated output power in method F1 There are also simplified methods based on no-load and locked-rotor tests only, as described in [23].

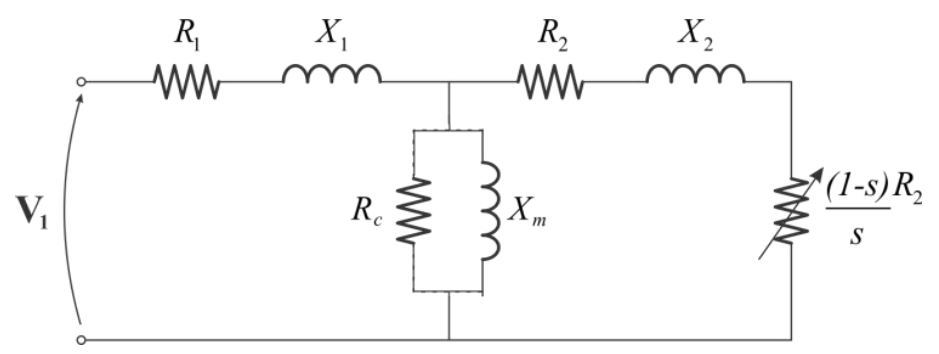

Fig. 2. Per-phase equivalent circuit of a PPIM [11].

For SPIMs, however, the equivalent circuit depicted in Fig. 3, based on the revolving field theory [19] and valid only for machines with a single run winding, is only briefly presented in [12] and no test procedures for parameter determination are described. Traditional methods for this purpose employ no-load and locked rotor tests with simplifying assumptions [23].

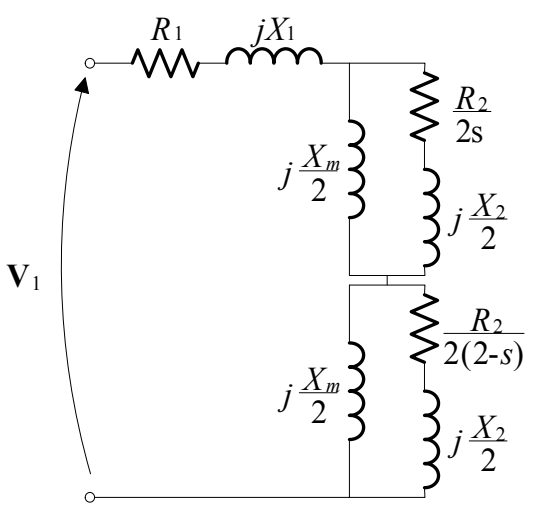

Fig. 3. Single winding SPIM equivalent circuit[12].

For SPIMs with multiple run windings, the circuit must consider the effects of both windings and their interactions, as illustrated in Fig. 4 [19] for capacitor motors, commonly used in compressors. Here, $\mathbf{V}_{m}$ and $\mathbf{V}_{a}$ are terminal voltage phasors of the main and auxiliary windings, $\mathbf{E}_{\mathrm{f}}$ and $\mathbf{E}_{b}$ are emf phasors related to the forward and backward rotating fields, $R_{c a p}$ and $X_{c a p}$ are the capacitor resistance and reactance, and the subscripts $m$ and $a$ relate to the main and the auxiliary windings, respectively. 


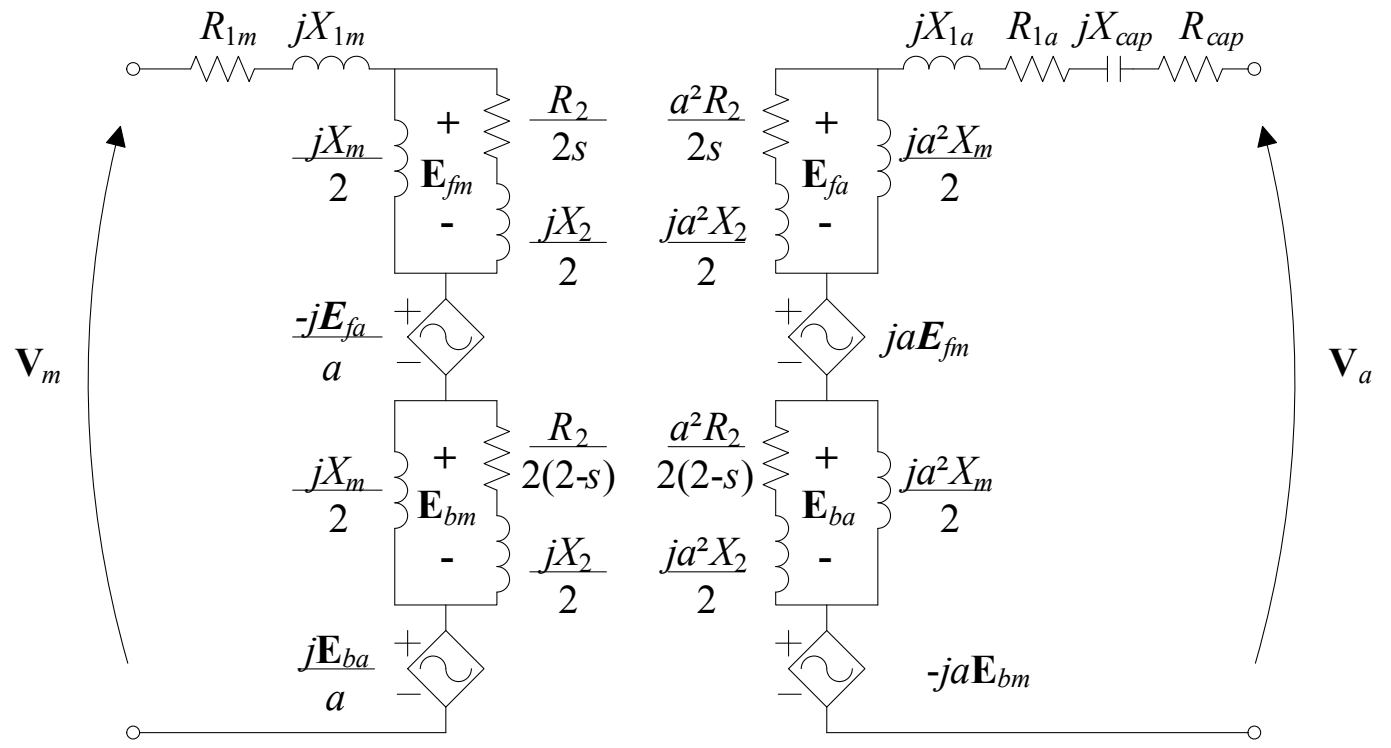

Fig. 4. Permanent capacitor SPIM equivalent circuit [19].

The determination of the parameters of this circuit, described in detail in [24], involves only electrical measurements of DC resistance, locked-rotor and no-load tests, and the winding ratio test as described in [18], if this value is not known. An alternative is presented in [25], employing a twophase supply with phase voltages scaled according to the winding ratio in order to cancel the backward field, thus enabling the application of the polyphase procedure.

The main advantages of the equivalent circuit method are the simple instrumentation and the possibility to calculate the performance for a wide operating range, although single-cage models are not expected to be accurate at higher slips [26]. On the downside, its application for multiple winding motors depends on non-standard methods, and the segregation of losses is preferred in standards [11].

\section{METHOD SELECTION GUIDELINES FOR COMPRESSOR MOTORS}

The most adequate test method for a compressor induction motor depends on a series of factors: the type of the machine (PPIM, single or multiple winding SPIM); which quantities can be measured, depending on the available test facilities and on the acceptable intrusiveness; and whether the result is desired to be supported by a test standard.

The main characteristics of the presented test methods for polyphase induction motors are summarized in Table I. According to [11],the preferred method should be the input-output method with segregation of losses, whenever possible. The direct method should be limited to fractional horsepower machines. Both require torque measurements, meaning that the machine must be coupled to a dynamometer. Two techniques for dynamometer testing are presented in the next section. If such tests are not possible, methods E, E1, F and F1 are recommended [11]. The direct measurement of stray-load loss included in methods $\mathrm{E}$ and $\mathrm{F}$ requires the removal of the rotor, which would hardly be more practical than dynamometer tests, therefore these methods are excluded from this selection. In methods E1 and F1, on the other hand, the stray-load loss is assumed as a percentage of the rated 
output power, offering convenience at the cost of precision. In method E1, aside from electrical measurements, it is necessary to load the motor and to accurately measure the speed; in F1, according to the chosen impedance test, it may be necessary to lock the rotor, to impose load or to measure speed accurately. These requirements are achievable without any damage to the compressor by measuring speed through alternative means (e.g. by current [27], vibration or acoustic signal analysis), by locking the rotor through compressor stalling and by modulating the load through the control of suction and discharge pressures and temperatures [17]. In the IEC segregation of losses [13], the accuracy provided by the measurement of $P_{\text {sll }}$ is an advantage over the E1 method with almost no additional intrusion. The conventional equivalent circuit determination is expected to be the least precise, but also the simplest.

TABLE I. SUMMARY OF METHODS FOR THREE-PHASE MOTORS

\begin{tabular}{|c|c|c|c|c|c|c|c|c|}
\hline \multicolumn{2}{|c|}{ Method } & \multirow{2}{*}{$\begin{array}{c}\begin{array}{c}\text { DC resistance } \\
\text { measurement }\end{array} \\
X\end{array}$} & \multirow[t]{2}{*}{$\begin{array}{c}\text { No-load } \\
\text { test }\end{array}$} & \multirow[t]{2}{*}{ LRT } & \multirow{2}{*}{$\begin{array}{c}\begin{array}{c}\text { Load } \\
\text { test }\end{array} \\
X\end{array}$} & \multirow{2}{*}{$\begin{array}{c}\begin{array}{c}\text { Speed } \\
\text { measurement }\end{array} \\
\mathrm{X}\end{array}$} & \multirow{2}{*}{$\begin{array}{c}\begin{array}{c}\text { Torque } \\
\text { measurement }\end{array} \\
\mathrm{X}\end{array}$} & \multirow[t]{2}{*}{$\begin{array}{c}\text { Other } \\
\text { tests }\end{array}$} \\
\hline \multirow{6}{*}{ 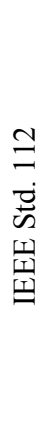 } & Direct (A) & & & & & & & \\
\hline & $\begin{array}{l}\text { Input-output } \mathrm{w} / \text { loss } \\
\text { segregation }(\mathrm{B})\end{array}$ & $\mathrm{X}$ & $\mathrm{X}$ & & $\mathrm{X}$ & $\mathrm{X}$ & $\mathrm{X}$ & \\
\hline & Loss segregation (E1) & $\mathrm{X}$ & $\mathrm{X}$ & & $\mathrm{X}$ & $\mathrm{X}$ & & \\
\hline & $\begin{array}{l}\text { Equivalent circuit (F1) - } \\
\text { Impedance tests } 1 \text { and } 2\end{array}$ & $X$ & $X$ & $*$ & & & & \\
\hline & $\begin{array}{l}\text { Equivalent circuit (F1) - } \\
\text { Impedance test } 3\end{array}$ & $\mathrm{X}$ & $\mathrm{X}$ & & $* *$ & $\mathrm{X}$ & & \\
\hline & $\begin{array}{l}\text { Equivalent circuit (F1) - } \\
\text { Impedance test } 4\end{array}$ & $\mathrm{X}$ & $\mathrm{X}$ & $\mathrm{X}$ & $\mathrm{X}$ & $\mathrm{X}$ & & \\
\hline & $\begin{array}{l}\text { 0034-2-1 Loss segregation } \\
\text { w/ Eh-Star }\end{array}$ & $\mathrm{X}$ & $X$ & & $\mathrm{X}$ & $X$ & & EH-Star \\
\hline & $\begin{array}{l}\text { Equivalent circuit - } \\
\text { Conventional[23] }\end{array}$ & $\mathrm{X}$ & $\mathrm{X}$ & $\mathrm{X}$ & & & & \\
\hline
\end{tabular}

*Reduced frequency **Reduced voltage or load imposition

A summary of methods applicable to SPIMs with a single run winding is presented in Table II. The standard [12]supports all three approaches (direct, loss segregation and equivalent circuit), although the procedure of the latter is not described. The segregation proposed by Veinott offers no advantages in terms of convenience over the standard procedure for these motors.

TABLE II. SUMMARY OF METHODS FOR SINGLE RUN-WINDING SPIMS

\begin{tabular}{|c|c|c|c|c|c|c|c|}
\hline Method & $\begin{array}{l}\text { DC resistance } \\
\text { measurement }\end{array}$ & $\begin{array}{c}\text { No-load } \\
\text { test }\end{array}$ & LRT & $\begin{array}{c}\text { Load } \\
\text { test }\end{array}$ & $\begin{array}{c}\text { Speed } \\
\text { measurement }\end{array}$ & $\begin{array}{c}\text { Torque } \\
\text { measurement }\end{array}$ & $\begin{array}{c}\text { Other } \\
\text { tests }\end{array}$ \\
\hline IEEE Std. 114 Direct & $\mathrm{X}$ & & & $\mathrm{X}$ & $\mathrm{X}$ & $\mathrm{X}$ & \\
\hline $\begin{array}{l}\text { IEEE Std. } 114 \text { Loss } \\
\text { segregation }\end{array}$ & $\mathrm{X}$ & $\mathrm{X}$ & $\mathrm{X}$ & $\mathrm{X}$ & $\mathrm{X}$ & & \\
\hline $\begin{array}{c}\text { Veinott's loss } \\
\text { segregation [18] }\end{array}$ & $\mathrm{X}$ & $\mathrm{X}$ & $\mathrm{X}$ & $\mathrm{X}$ & $\mathrm{X}$ & & \\
\hline Equivalent circuit[23] & $\mathrm{X}$ & $\mathrm{X}$ & $\mathrm{X}$ & & & & \\
\hline
\end{tabular}

The test methods applicable to multiple run winding SPIMs are summarized in Table III. The only method proposed in the standard [12] is the direct method. Veinott's loss segregation is referenced in the standard and offers the possibility to test the motor without any damage to the compressor, as 
previously discussed. The same applies to the equivalent circuit methods, which tend to be less precise due to the inherent simplifications.

TABLE III. SUMMARY OF METHODS FOR MULTIPLE RUN WINDING SPIMS

\begin{tabular}{|c|c|c|c|c|c|c|c|}
\hline Method & $\begin{array}{l}\text { DC resistance } \\
\text { measurement }\end{array}$ & $\begin{array}{c}\text { No-load } \\
\text { test }\end{array}$ & LRT & $\begin{array}{c}\text { Load } \\
\text { test }\end{array}$ & $\begin{array}{c}\text { Speed } \\
\text { measurement }\end{array}$ & $\begin{array}{c}\text { Torque } \\
\text { measurement }\end{array}$ & $\begin{array}{c}\text { Other } \\
\text { tests }\end{array}$ \\
\hline IEEE Std. 114 Direct & $\mathrm{X}$ & & & $\mathrm{X}$ & $\mathrm{X}$ & $\mathrm{X}$ & \\
\hline $\begin{array}{c}\text { Veinott's loss } \\
\text { segregation }[18]\end{array}$ & $\mathrm{X}$ & $\mathrm{X}$ & $\mathrm{X}$ & $\mathrm{X}$ & $\mathrm{X}$ & & $*$ \\
\hline Equivalent circuit [24] & $\mathrm{X}$ & $\mathrm{X}$ & $\mathrm{X}$ & & & & $*$ \\
\hline $\begin{array}{l}\text { Equivalent circuit - two } \\
\text { phase method [25] }\end{array}$ & $\mathrm{X}$ & $\mathrm{X}$ & $* *$ & $* *$ & $* *$ & & $*$ \\
\hline
\end{tabular}

\section{APPLICATION EXAMPLES}

Some of the presented methods were evaluated employing test data obtained previously from a batch of six compressors, whose data are summarized in Table IV. All of them have two poles and operate at $220 \mathrm{~V}$ and $60 \mathrm{~Hz}$. The machines had been purchased for research purposes and subjected to calorimeter tests, when the input power was measured for a series of reference conditions. Damaging the compressors was acceptable, and compliance with test standards was desired.The TPIMs were tested through method B of IEEE Std. 112, except for motor 3, which had unsymmetrical windings and had to be tested through the direct method. All three SPIMs are capacitor-run and have been tested through the direct method to comply with IEEE Std. 114. The rated input power was assumed as reference since the rated output power was unknown. A temperature test would be illogical since there is no refrigerant flowing, thus the specified temperature was assumed as $80^{\circ} \mathrm{C}$.

TABLE IV. DATA OF THE TESTED COMPRESSORS

\begin{tabular}{ccccc}
\hline Compressor & Number of phases & Rated input power $\mathbf{( k W )}$ & Type & Rating (kBTU/h) \\
\hline 1 & 3 & 1.62 & Reciprocating & 18 \\
2 & 3 & 3.41 & Reciprocating & 38 \\
3 & 3 & 3.49 & Scroll & 36 \\
4 & 1 & 1.70 & Scroll & 18 \\
5 & 1 & 1.61 & Rotary & 18 \\
6 & 1 & 3.60 & Rotary & 36 \\
\hline
\end{tabular}

\section{A. Frame replacement}

In order to enable dynamometer tests in a horizontal test bench, the frame was replaced by a horizontal adjustable frame, depicted in Fig. 5, and the single sided shafts by double-sided brass ones. The shaft height was adjustable manually through screws. The tests could then be carried out on the test bench depicted in Fig. 6, installed in the Electrical Engineering Department of the University. The motor was supplied with a three-phase programmable source and coupled to a load machine. An HBM in-line transducer provided signals of torque and speed, which were acquired through an HBM module and processed in LabVIEW. Electrical measurements were performed with a Yokogawa 
power analyzer. A bench multimeter was employed for resistance measurement in four-wire setting, and a data logger recorded the motor and the ambient temperature signals from two thermocouples. The electrical connections are depicted in Fig. 7 and illustrate how the capacitor losses and voltage drop were excluded from the measurements. While the possibility to employ horizontal test benches is an advantage of this approach, the main drawbacks are the complexity of airgap adjustment, the risk of shaft eccentricity, the damage to the compressor frame and the change in the friction and windage losses caused by the bearing substitution.

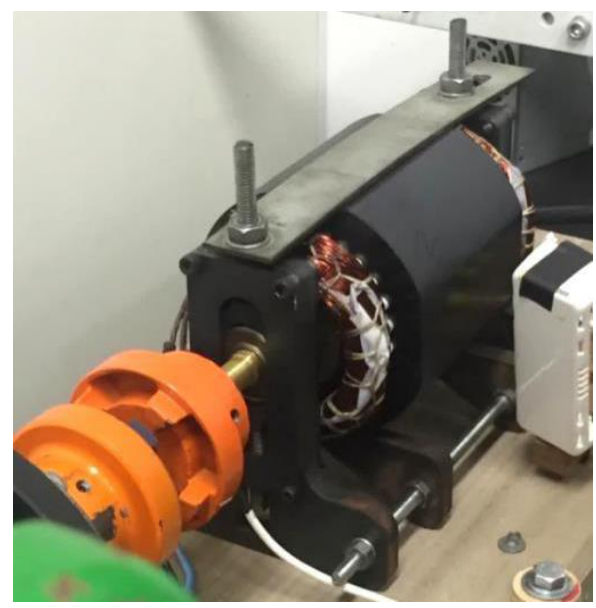

Fig. 5. Motor with custom horizontal frame.

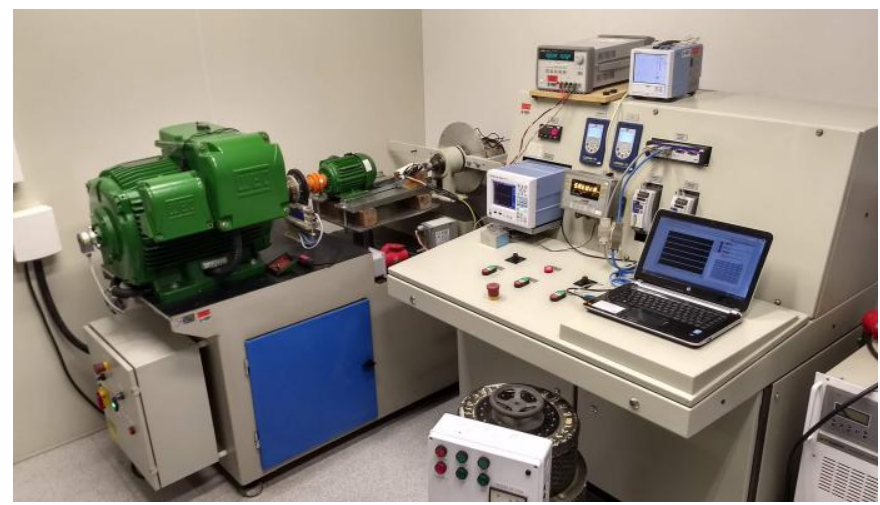

Fig. 6. Test bench for electric motors.

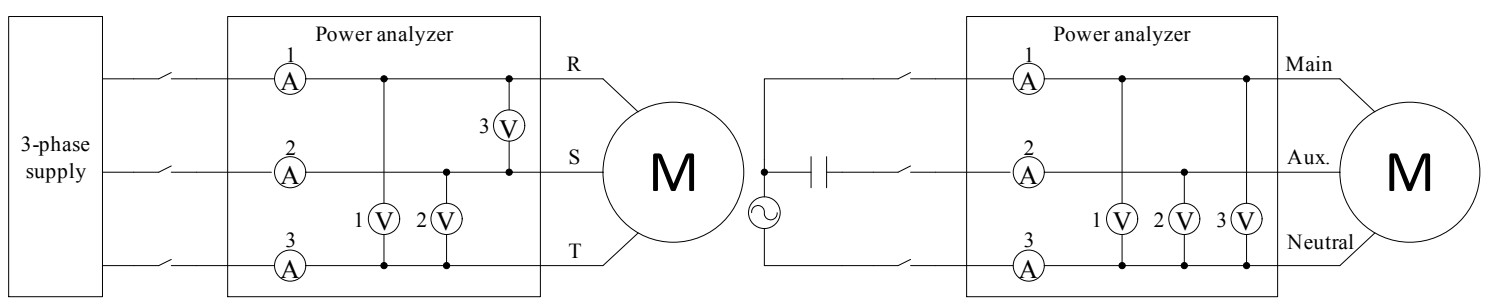

Fig. 7. Electrical connections in tests with three-phase (left) and single-phase motors (right).

\section{B. Original frame}

A second approach was employedto repeat tests with a new sample of compressor 5 in a more practical way. As shown in Fig. 8, a horizontal test bench containing an electromagnetic brake was adapted to allow the test of vertical motors. The cap of the compressor frame was sawn off, and a 
brass shaft was screwed to the rotor. The suction and discharge ducts were open, thus the mechanism ran idle as there was no pressure difference. The torque was measured by a load cell attached to the arm that supports the brake coils, and the speed was measured with an optical tachometer. Aside from the torque and speed adaptations, the same instruments of the horizontal bench were used.

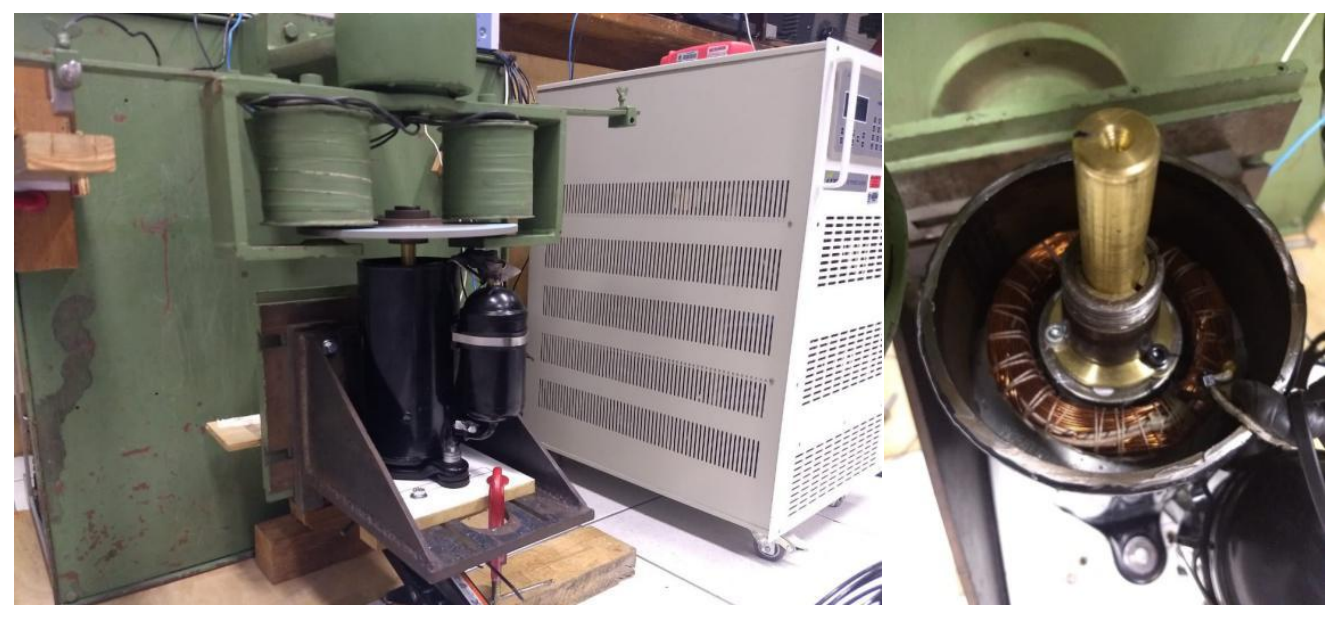

Fig. 8. Motor 5 and test bench adapted for vertical testing (left) and shaft extension (right).

Despite the need for a special or adapted test bench, this approach avoids the need to remove the motor and to build a custom frame. It also offers a realistic evaluation of the motor losses, especially of $P_{f w}$, that includes the effect of all moving parts of the compressor. Care must be taken not to block the oil flow through channels inside the shaft, which may cause a permanent rotor blockage.

\section{RESULTS}

The efficiency and losses curves obtained for motor 1 through IEEE 112 method B are presented in Fig. 9. The markers indicate the six test points of the load test. While it is common to plot these curves as functions of slip or output power, in the present context it is useful to represent the input power in the horizontal axis. This facilitates further applications, e.g. the determination of the motor losses for a given condition observed in calorimeter tests or in normal operation, when the slip or the output power would not be observable. The loss distribution presented in Fig. 10 shows the dominance of the joule losses and the negligible contribution of the stray-load loss for this motor. Similar results were obtained for motor2 as shown in Fig. 11, with more significant stray-load loss. 


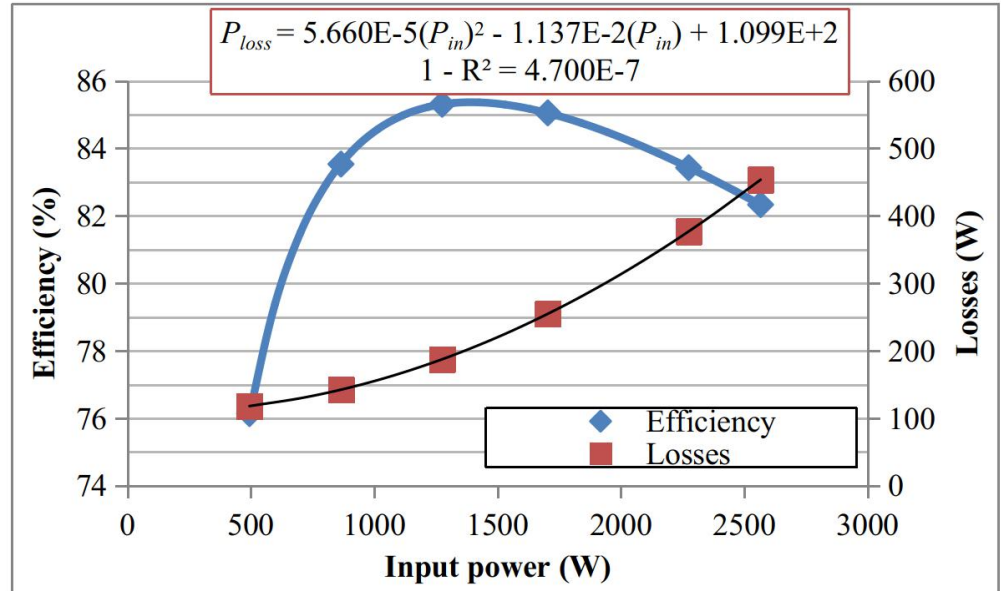

Fig. 9. Efficiency and losses curves of motor 1.

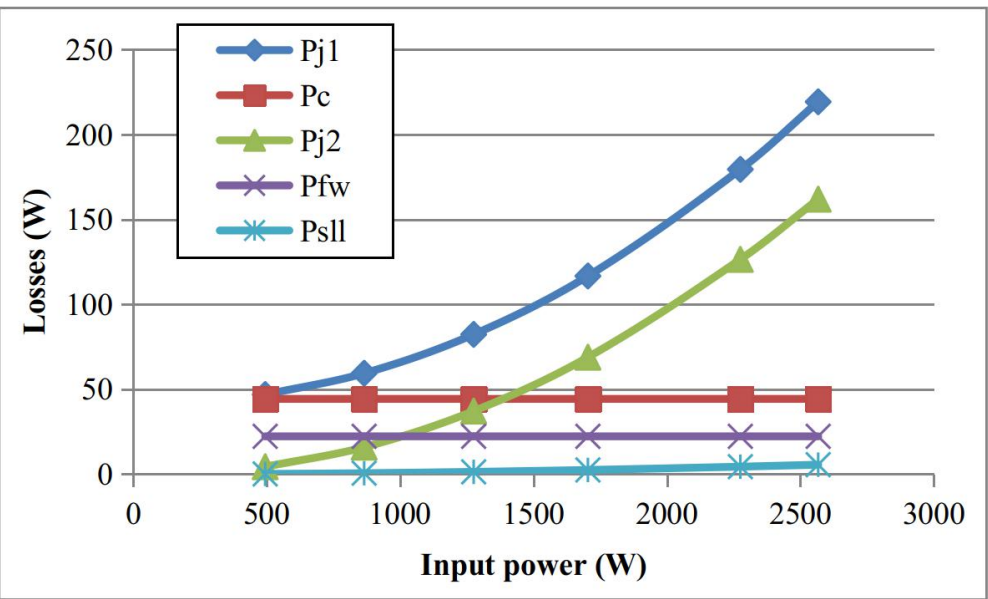

Fig. 10. Losses distribution of motor 1.

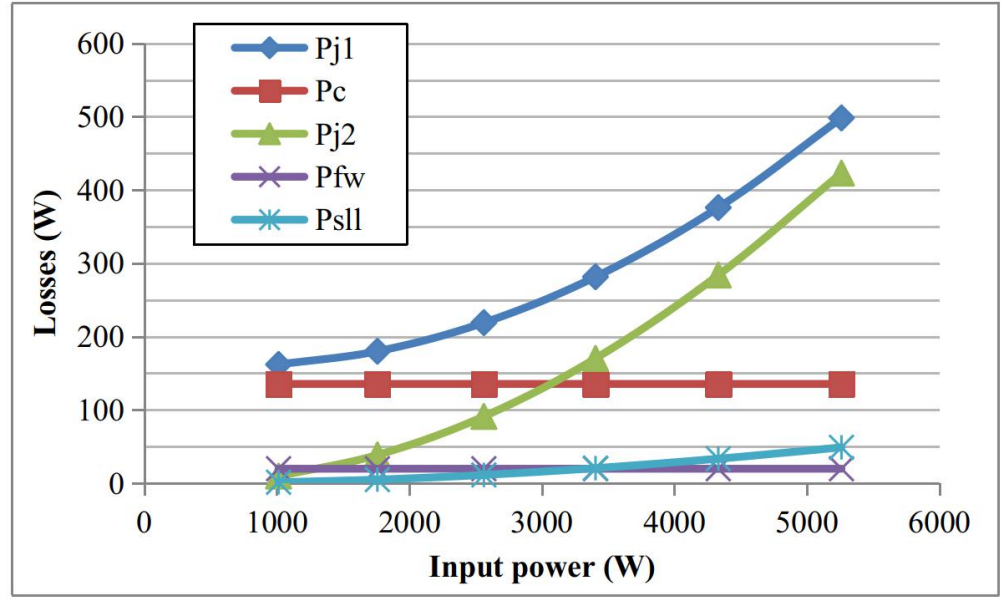

Fig. 11. Losses distribution of motor 2.

The efficiency and losses curves obtained for motor 3 through the direct method (IEEE Std. 112 method A) are presented in Fig. 12. Even though a simpler method was used, a fitted curve with high determination factor $\left(R^{2}\right)$ has been achieved as well. Since $R^{2}$ is close to unity, the value $1-R^{2}$ is indicated in the figures instead of $\mathrm{R}^{2}$. 


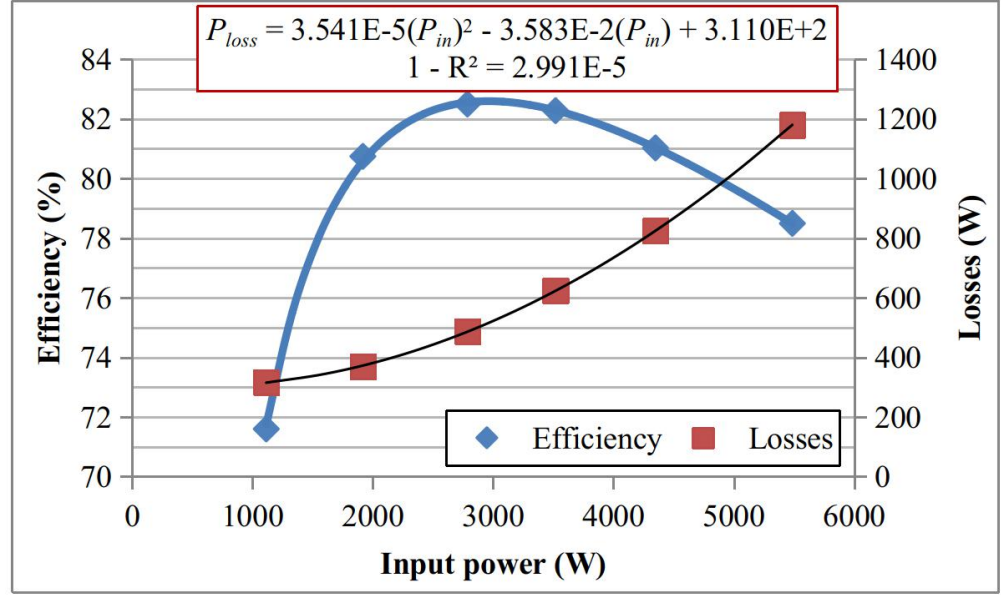

Fig. 12. Efficiency and losses curves for motor 3.

In order to compare these results with those of less intrusive methods, the test data from method B was used to determine the losses through methods E1 and F1 for motor 1. Other methods that include locked-rotor measurements were not considered because no such data was collected at the time of the tests. The same resistance, no-load and load test data was used in the calculations of methods B and E1. The main difference is the calculation of stray-load loss, assumed as $1.8 \%$ of the converted power in method E1 after the subtraction of the remaining losses. For method F1, the stray-load losses determined in the same manner, and the calculation of the equivalent circuit parameters is performed by considering the load test measurements at rated condition as the rated slip impedance test. The resulting parameters, corrected to $80^{\circ} \mathrm{C}$, are presented in Table $\mathrm{V}$.

TABLE V. EQUIVALENT CIRCUIT PARAMETERS OF MOTOR 1.

\begin{tabular}{ccccc}
\hline $\boldsymbol{R}_{\mathbf{1}}(\boldsymbol{\Omega})$ & $\boldsymbol{R}_{\mathbf{2}}(\boldsymbol{\Omega})$ & $\boldsymbol{X}_{\mathbf{1}}=\boldsymbol{X}_{\mathbf{2}}(\boldsymbol{\Omega})$ & $\boldsymbol{R}_{c}(\boldsymbol{\Omega})$ & $\boldsymbol{X}_{\boldsymbol{m}}(\boldsymbol{\Omega})$ \\
\hline 1.224 & 1.103 & 2.377 & 871.7 & 41.53 \\
\hline
\end{tabular}

The resulting losses calculated through these methods are compared in Fig. 13, which shows losses curves as a function of input power determined by each method and relative deviations of methods E1 and $\mathrm{F} 1$ assuming method $\mathrm{B}$ as reference. The differences observed between methods $\mathrm{B}$ and $\mathrm{E} 1$ are solely caused by the different values of $P_{\text {sll }}$, whose assumed value is ten times greater than the one measured through method B. The results of method F1 are very similar to those of method E1. A 10\% deviation in the total loss is observed at the rated condition (fourth point from left to right), reaching more than $15 \%$ at the highest load. 


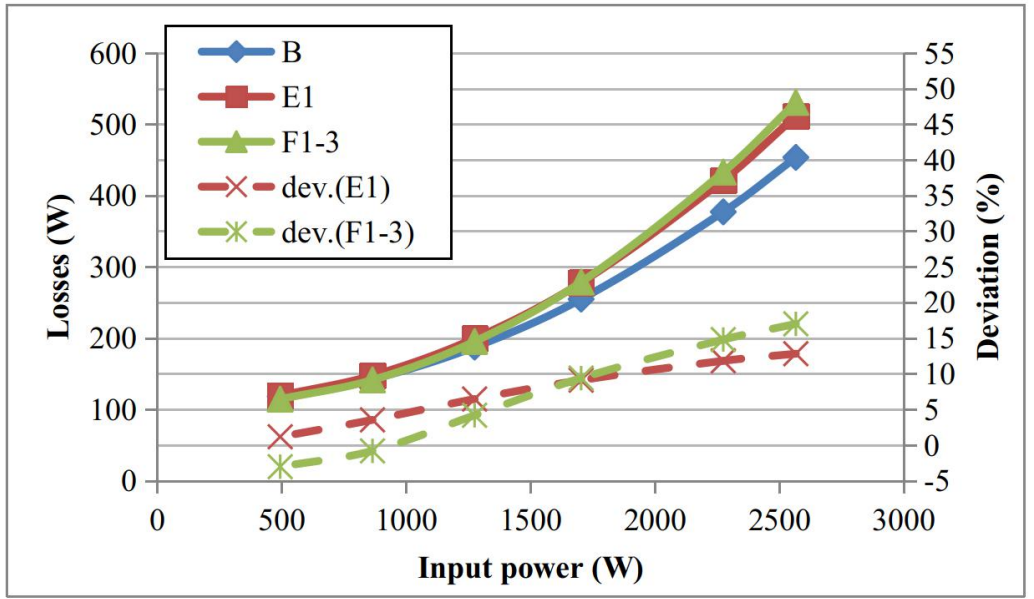

Fig. 13. Comparison between methods B, E1 and F1 for motor 1 .

The efficiency and losses curves obtained for motor 5, a capacitor-run SPIM tested by the direct method in the vertical dynamometer, are presented in Fig. 14. The results are comparable to those of motor 1 , which also drives an $18 \mathrm{kBTU} / \mathrm{h}$ compressor and operates with practically the same input power at rated condition. Unlike the three-phase case, the losses do not decrease monotonically with the load, but achieve its minimum at a certain load level. The loss segregation in these motors was not possible due to the lack of winding ratio and locked-rotor data. Nevertheless, a high value of $\mathrm{R}^{2}$ of the fitted loss curve has been achieved. Similar results were obtained for the other SPIMs.

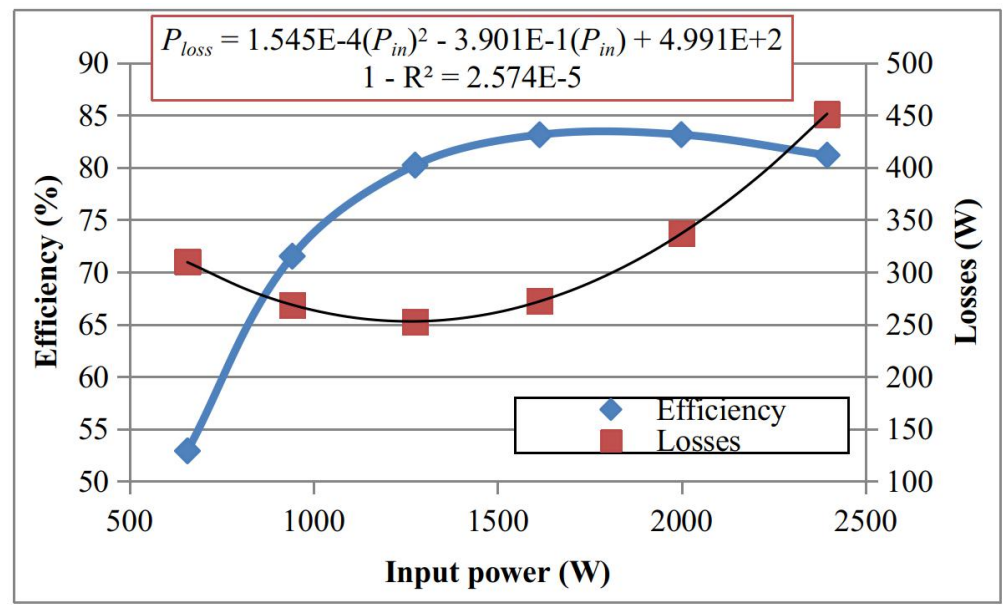

Fig. 14. Efficiency and losses curves of motor 5.

All motors tested in the custom horizontal frame presented similar values of $P_{f w}$ around $20 \mathrm{~W}$, since the same bearings were used. Motor 5, tested in its original frame, presented a $P_{f w}$ of $105.5 \mathrm{~W}$, reflecting the effect of the compression mechanism running idle.

\section{CONCLUSIONS}

This paper presented an overview of efficiency test methods for induction machines embedded in hermetic compressors. The great variety of standard methods available for polyphase machines provides options with different levels of intrusion and complexity that can be chosen according to the circumstances. For single-phase machines, however, few options are described in standards, where dynamometer tests are indicated as the only option for SPIMs with more than one run winding. Less 
intrusive options based on loss segregation and on equivalent circuits were found in the literature.

The tests that compose these methods have been summarized to guide the choice of the most suitable option depending on the circumstances. The selection criteria include the type of induction motor, the desired level of preservation of the compressor frame, the compliance with technical standards and the available test facilities. Through some of the presented options, it is possible to determine the losses of the motor without accessing it, i.e., without damaging the compressor frame.

Some of the presented methods have been applied to the determination of losses and efficiency of single and three-phase motors employing test data obtained in past studies. Two practical approaches that allowed dynamometer testing of these motors have been presented. The approach that preserves the original compressor frame was shown to be less time-demanding than the frame replacement, as it does not demand airgap adjustments. This was aggravated by small eccentricities observed in some of the rotors whose shafts were replaced.

The comparison has indicated that the determination of stray-load loss represents an important difference between methods. If speed measurement is possible, non-intrusive methods may achieve results comparable to those of dynamometer tests. A full comparison between all the presented methods was not possible since the required data was not measured at the time when the tests were carried out, and the tested compressors are no longer available. This may be achieved in future works.

\section{ACKNOWLEDGMENT}

This work was made possible by the project PD-0403-0034/2013 of ENGIE Brasil Energia's R\&D Program, regulated by ANEEL, and was supported by the Brazilian National Council for Scientific and Technological Development - CNPq.

\section{REFERENCES}

[1] IEA, "The Future of Cooling", IEA, Paris, 2018. Available at www.iea.org/reports/the-future-of-cooling.

[2] R. Z. Wang, X. Yu, T. S. Ge, and T. X. Li, "The present and future of residential refrigeration, power generation and energy storage", Applied Thermal Engineering, vol. 53, no.2, pp. 256-270, 2013.

[3] A. M. Gaikwad et al,"Results of residential air conditioner testing in WECC", in IEEE Power and Energy Society General Meeting-Conversion and Delivery of Electrical Energy in the 21st Century, Pittsburgh, 2008.

[4] F. J. H. Kalluf, L. N. Tutelea, I. Boldea,and A. Espindola, "2/4-POLE split-phase capacitor motor for small compressors: A comprehensive motor characterization”, IEEE Trans. on Ind. Applications, vol. 50, no.1, 2013.

[5] P. Lin and V. Avelar, "The different types of cooling compressors", A Journal of Different Technologies for Cooling Data Centres, 2017.

[6] M. Ozu and T. Itami, "Efficiency analysis of power consumption in small hermetic refrigerant rotary compressors", International Journal of Refrigeration, 1981.

[7] C. D. Pérez-Segarra, J. Rigola, M. Sòria, and A. Oliva, "Detailed thermodynamic characterization of hermetic reciprocating compressors", Int. Journal of Refrigeration, vol. 28, pp. 579-593, 2005.

[8] H. Wakabayashi, J. Yuuda, T.Aizawa,and M. Yamamura, "Analysis of performance in a rotary compressor", in Int.Compressor Engineering Conference, 1982.

[9] U. C. Park, "Transient analysis of a variable speed rotary compressor", Energy Conversion and Management, vol. 51, no.2, pp. 277-287, 2010 .

[10] M. C. Diniz, C. Melo, and C. J. Deschamps, "Experimental performance assessment of a hermetic reciprocating compressor operating in a household refrigerator under on-off cycling conditions", International Journal of Refrigeration, vol. 88, pp. 587-598, 2018.

[11] Standard Test Procedure for Polyphase Induction Motors and Generators, IEEE Standard 112, 2018.

[12] Standard Test Procedure for Single-Phase Induction Motors, IEEE Standard. 114, 2010.

[13] Rotating electrical machines - Part 2-1: Standard methods for determining losses and efficiency from tests (excluding machines for traction vehicles),Int. Standard IEC 60034-2-1, 2014. 
Journal of Microwaves, Optoelectronics and Electromagnetic Applications, Vol. 20, No. 3, September 2021

[14] K. W. Lee, J. Hong, S. B. Lee,and S. Lee, "Quality assurance testing for magnetization quality assessment of BLDC motors used in compressors", IEEE Trans. on Ind. Applications, 2010.

[15] E. Agamloh and A. S. Nagorny, "An overview of efficiency and loss characterization of fractional horsepower motors", IEEE Trans. on Industrial Electronics, 2012.

[16] E. Winandy, C. Saavedra, and J. Lebrun, "Experimental analysis and simplified modelling of a hermetic scroll refrigeration compressor", Applied thermal engineering, 2002.

[17] C. Cuevas, J. Lebrun, V. Lemort,and E. Winandy, "Characterization of a scroll compressor under extended operating conditions," Applied thermal engineering, 2010.

[18] C. G. Veinott, "Segregation of losses in single phase induction motors", Trans. of the AIEE, 1935.

[19] W. J. Morrill, "The revolving field theory of the capacitor motor", Trans. of the AIEE,1929.

[20] B. Lu, T. G. Habetler, and R. G. Harley, "A survey of efficiency-estimation methods for in-service induction motors", IEEE Trans. Ind. Appl., vol. 42, no. 4, pp. 924-933, 2006.

[21] H. A. Toliyat, E. Levi, and M. Raina, "A review of RFO induction motor parameter estimation techniques", IEEE Trans. Energy Convers., vol. 18, no. 2, pp. 271-283, 2003.

[22] P. Pillay, V. Levin, P. Otaduy, and J. D. Kueck, "In-Situ Induction Motor Efficiency Determination Using the Genetic Algorithm", IEEE Trans. Energy Conversion, vol. 13, no. 4, pp. 326-333, 1998.

[23] V. D. Toro, Electric Machines and Power Systems, Prentice-Hall, 1988.

[24] F. W. Suhr, "Toward an Accurate Evaluation of Single-Phase Induction-Motor Constants", Trans. of the AIEE. Part III: Power Apparatus and Systems, vol. 71, no. 1, pp. 221-227, Jan. 1952.

[25] C. van der Merwe and F. S. van der Merwe, "A study of methods to measure the parameters of single-phase induction motors,"IEEE Trans. on Energy Conversion, vol. 10, no. 2, pp. 248-253, June 1995.

[26] J. Pedra and F. Córcoles, "Estimation of Induction Motor Double-Cage Model Parameters From Manufacturer Data", IEEE Trans. on Energy Conversion, vol. 19, no. 2, pp. 310-317, 2004.

[27] K. D. Hurst and T. G. Habetler, "Sensorless speed measurement using current harmonic spectral estimation in induction machine drives", IEEE Trans. on Power Electronics, vol. 11, no. 1, pp. 66-73, Jan. 1996. 